\title{
Pengaruh Satisfaction, Brand Love terhadap Brand Loyalty dan Word of Mouth
}

\section{Edy Purwanto*, M. Munir Syam AR}

Fakultas Ekonomi dan Bisnis, Universitas Wiraraja

Sumenep, Indonesia

\begin{abstract}
This study aims to examine and determine the effect of consumer satisfaction, brand love on loyalty and WOM, and the influence of customer loyalty on WOM. The object of this research is Batik in Sumenep Regency. The sample for this study consisted of 200 people who were selected using the purposive sampling technique. The questionnaire was distributed to collect data. Path analysis and structural equation modeling were used in the test. Results-Based on this research, the variable of satisfaction has an influence on loyalty and word of mouth, love of the brand has an effect on loyalty, and customer loyalty has an effect on WOM. But the variable love of the brand has no significant effect on word of mouth. It is hoped that the research can provide information about the ability of satisfaction and brand love in influencing consumer loyalty and the ability of satisfaction and loyalty in influencing consumers to carry out the word of mouth. Furthermore, this research is useful for clothing business actors in the batik industry in developing appropriate strategies in developing their businesses.
\end{abstract}

\section{Keywords:}

Satisfaction, Brand Love, Loyalty, WOM, Batik

\section{Corresponding Author:}

\section{Edy Purwanto}

Fakultas Ekonomi dan Bisnis, Universitas Wiraraja

Jl. Raya Sumenep Pamekasan Km. 05, Sumenep, Indonesia

Email korespondensi: edypurwanto@wiraraja.ac.id

(C) The Author(s) 2021

DOI: https://doi.org/10.36407/jmsab.v5i1.434

\section{Research Paper \\ Marketing Strategic}

Received: 08 Sep 2021

Accepted: 10 Jan 2022

Online: 25 Jan 2022

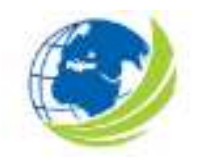

Jurnal Manajemen Strategi dan Aplikasi Bisnis, Vol 5, No. 1, 2022, pp. $17-32$

eISSN 2655-237X

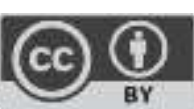

CC BY: This license allows reusers to distribute, remix, adapt, and build upon the material in any medium or format, so long as attribution is given to the creator. The license allows for commercial use. 


\section{PENDAHULUAN}

Batik adalah salah satu bagian dari kebudayaan dan telah menjadi fenomena di Indonesia (Prayitno, 2020). Dari dulu hingga sekarang, batik sudah menjadi seni dan kerajinan masyarakat. Batik adalah kain yang digambar dan diproses dengan teknik tertentu sehingga memiliki kekhasan. Indonesia memiliki banyak motif dan corak batik yang tersebar di seluruh nusantara. Salah satu Kota penghasil Batik di Indonesia yaitu Kabupaten Sumenep. Beberapa merek Batik yang ada di Kabupaten Sumenep diantaranya adalah Batik Canteng Koneng, Batik Tulis Melati, dan Batik Tulis Al-Barokah. Batik tersebut memiliki karakteristik yang berbeda-beda. Misalkan batik canting koneng yang memiliki warna yang lebih pekat dan juga lebih terang ketika digunakan.

Kepuasan konsumen batik merupakan faktor penting yang perlu diperhatikan oleh para pemasar. Sebab, saat ini dunia usaha mengalami peningkatan persaingan dan hal itu dapat menjadi dasar dalam memperkuat hubungan dengan pelanggan (Tripathy, 2017). Kepuasan merupakan salah satu faktor penting dalam industry batik. Konsumen yang merasa puas dapat mendorong konsumen mejadi loyal (Santini et al., 2018) dan cenderung menyampaikan informasi positif kepada orang lain (Khan et al., 2020). Dengan begitu, kepuasan konsumen merupakan hal yang perlu diperhatikan agar loyalitas konsumen dalam membeli dan menggunakan batik dapat terjaga dan bahkan sorang konsumen bisa menyebarkan ionformasi positif terhadap orang-orang yang ada di lingkunga sekitarnya.

Strategi dalam menyentuh emosi konsumen telah menjadi fenomena yang menarik dalam manajemen (Bairrada et al., 2019). Salah satu variabel yang mengukur hubungan emosional konsumen tersebut yaitu variabel kecintaan terhadap merek (brand love). Brand love merupakan perasaan positif yang mencerminkan keterikatan emosional terhadap sebuah merek (Ferreira et al., (2020). Kecintaan terhadap terhadap merek juga diangap sebagai tingkat keterikatan emosional konsumen terhadap suatu merek atau produk tertentu. Brand love mencakup sejumlah tanggapan afektif terhadap merek, termasuk gairah, keterikatan, evaluasi positif, emosi positif, dan pernyataan cinta. Gagasan cinta merek berakar pada teori cinta interpersonal (Carroll dan Ahuvia, 2006). Kecintaan seseorang terhadap batik sangat menarik untuk dikaji terutama bagaimana dampak kecintaan konsumen terhadap batik terhadap loyalitas konsumen dan keinginannya dalam menyampaikan informasi mengenai suatu merek.

Loyalitas konsumen untuk terus menggunakan batik merupakan impian para praktisi dan juga pemerintah sebagai wujud kecintaan terhadap budaya Indonesia. Apalagi pengusaha batik yang selalu berharap agar konsumen Indonesia selalu memiliki kepedulian untuk menggunakan dan membeli batik di Indonesia. Loyalitas merek merupakan salah satu konsep penting bagi perusahaan dalam melakukan pemasaran (Kandampully et al., 2015). Selain itu, faktor yang perlu diperhatikan juga adalah informasi yang disampaikan konsumen setelah menggunakan batik. Istilah ini dalam penelitian marketing dikenal dengan istilah word of mouth. Loyalitas konsumen terhadap batik menjadi kajian yang menarik mengingat keberlangsungan industry batik juga dipicu oleh tingkat loyalitas konsumen terhadap batik itu sendiri sehingga berujung pada pembelian. Pernyataan ini didukung dalam Literatur yang diadopsi oleh Pop dan Woratschek (2017) yang menyampaikan bahwa loyalitas konsumen lebih kepada komitmen konsumen untuk melakukan pembelian, berlangganan, dan menyukai sebuah produk/merek secara konsisten. 
Mengacu pada literatur sebelumnya, Wang et al., (2017) menyampaikan bahwa WOM merupakan komunikasi informal yang dilakukan oleh konsumen ke konsumen lain mengenai merek, produk, dan organisasi, atau layanan. WOM berarti berbagi pengalaman tentang konsumen kepada orang lain seperti teman, saudara, rekan kerja, dan lain sebagainya. Keinginan konsumen dalam menyampaikan informasi kepada keluarga, teman, dan orang-orang yang ada lingkungan sekitar konsumen sangat didukung oleh kepuasan (Khan, 2020., Wang et al., 2017), kecintaan (Loureiro et al., 2017., Karjalouto, 2016) dan loyalitas konsumen (Bicakglio 2016., Rialti et al., 2017). Semakin baik faktor-faktor tersebut maka semakin baik pula informasi yang disampaikan konsumen.

Model yang dikembangkan dalam penelitian ini yaitu analisis jalur. Dengan demikian rumusan masalah dalam penelitian adalah apakah variabel kepuasan dan brand love berpengaruh pada loyalitas dan word of mouth, apakah loyalitas berpengaruh pada word of mouth. Mengacu pada rumusana masalah tersebut sehingga dapat dibuat tujuan penelitian yaitu untuk mengetahui pengaruh variabel kepuasan dan brand love terhadap loyalitas dan WOM dan juga pengaruh loyalitas terhadap WOM. Penelitian ini diharapkan bisa memberikan informasi mengenai kemampuan kepuasan dan brand love dalam mempengaruhi loyalitas konsumen dan kemampuan kepuasan dan loyalitas dalam mempengaruhi konsumen untuk melakukan word of mouth. Selanjutnya, Penelitian ini berguna bagi para pelaku usaha pakaian di industri batik dalam menyusun strategi yang sesuai dalam mengembangkan usahanya.

Kebaharuan (novelty) dalam penelitian ini terletak pada pengembangan model konseptual yang digunakan dan menggunakan produk-produk budaya seperti batik. Tidak ada penelitian yang menggunakan model yang sama dengan konsep yang dikembangkan. Model penelitian yang paling dekat dalam penelitian ini yaitu penelitian yang dilakukan oleh Niyomsart dan Khamwon (2015) yang melakukan penelitian di Thailand dengan objek Airasia. Tetapi penelitian inI hanya menggunakan tiga variabel saja yaitu brand love, loyalitas dan word of mouth dan tidak menggunakan variabel kepuasan. Meskipun kepuasan seringkali didiskusikan dalam literatur marketing tetapi belum ada pengukuran yang jelas mengenai kepuasan konsumen (Hussein, 2018) dan kepuasan konsumen merupakan salah satu dasar dalam strategi marketing yang sangat penting (Roy, 2012). Dengan demikian, penggunaan variabel kepuasan dalam penelitian dirasa penting dan menarik untuk diteliti.

\section{KAJIAN PUSTAKA}

\section{Satisfaction}

Kepuasan konsumen dianggap sebagai konstruk yang sangat penting dalam pemasaran karena diyakini dapat mempengaruhi profitabilitas dan pangsa pasar (Flint et al., 2011). Selain itu, dari literature sebelumnya, Hussein (2018) menyampaikan bahwa kepuasan konsumen juga dipercaya sebagai rangkuman dari respon konsumen atas harapan konsumen sebelum membeli dengan yang didapatkan. Kepuasan konsumen merupakan seberapa baik pengalaman konsumen ketika menggunakan produk ketika dibandingkan dengan harapan konsumen waktu membeli produk tersebut (Razak dan Shamsudin, 2019). Harapan yang dimaksud adalah harapan yang dirasakan oleh konsumen sebelum membeli dan merasakan sebuah produk. Kepuasan pelanggan dapat membantu meningkatkan respon yang baik terhadap sebuah produk.

\section{Brand Love}

Dalam konteks merek, Bagozzi et al., (2017) menyampaikan bahwa kecintaan terhadap merek merupakan aspek yang sangat penting bagi konsumen maupun pemasar. Carroll dan Ahuvia (2006) menggambarkan cinta terhadap sebuah merek sebagai hubungan emosional pelanggan 
yang senang pada sebuah produk. Daya tarik merek, keterikatan merek, evaluasi merek positif, perasaan positif terhadap merek, dan ekspresi cinta konsumen terhadap merek adalah lima ciri merek. Selain itu, kecintaan terhadap merek bersifat lebih global karena biasanya merupakan hasil dari hubungan konsumen dengan perusahaan dari waktu ke waktu. Yang paling penting, cinta merek terkait erat dengan identitas konsumen, yang melibatkan integrasi merek ke dalam diri seorang konsumen.

\section{Loyalty}

Loyalitas didefinisikan sebagai serangkaian keputusan yang dibuat dari waktu ke waktu untuk mewakili pembelian terstruktur (Khan, 2013; Sari et al., 2020; Tabaku dan Zerellari, 2015). Loyalitas merek merupakan salah satu konsep dalam pemasaran yang telah dibuktikan sebagai konsep penting bagi perusahaan (Kandampully et al., 2015). Menurut Pappu dan Quester (2016), Loyalitas merek adalah ukuran hubungan pelanggan dengan suatu merek, dan itu memotivasi orang untuk membeli sebuah merek yang dipilih secara teratur (Rubio et al., 2017; Coelho et al., 2018).

\section{WOM}

Word of Mouth (WOM) adalah strategi komunikasi dalam pemasaran yang dapat memotivasi seseorang untuk menyampaikan pesan ke orang lain melalui informasi dari mulut ke mulut (Berger, 2014). Strategi ini mampu menyebarluaskan pesan secara efektif. Apabila konsumen puas terhadap sebuah merek, maka konsumen akan menyampaikan pengalaman positif mereka terhadap sebuah produk dan merekomendasikannya ke orang lain. Informasi dari mulut ke mulut dapat datang dari beberapa sumber seperti keluarga, teman dan para ahli. Saat ini, para pemasar setuju bahwa WOM sangat efisien dan handal ketika digunakan (Kimmel, 2010).

\section{Pengaruh kepuasan terhadap loyalitas}

Santini et al., (2018) melakukan meta analisis terhadap 256 penelitian kuantitatif di 73 jurnal yang ditelah dipublikasikan sejak tahun 2009 sampai tahun 2015. Penelitian tersebut menemukan bahwa kepuasan konsumen memiliki pengaruh pada loyalitas. Hasil yang sama juga ditemukan oleh dan Huang et al., (2017)., Pop dan Woratschek (2017). Penelitian yang menemukan bahwa kepuasan konsumen dapat berpengaruh pada Loyalitas konsumen dilakukan oleh Hussein (2018). Penelitian tersebut meneliti sebuah restaurant. Selain itu, Ferreira et al,, (2020) juga menemukan bahwa kepuasan yang dirasakan oleh konsumen memiliki dampak yang signifikan pada loyalitas konsumen. Penelitian tersebut melakukan penelitian dalam konteks Toko retail fashion di negara Portugal.

H1: Kepuasan berpengaruh positif pada loyalitas

\section{Pengaruh brand love terhadap loyalitas}

Hubungan antara brand love dan loyalitas merek sudah tertulis dengan jelas di banyak literatur. Bergkvist dan Bech-Larsen (2010) ditemukan kuat dukungan untuk hubungan ini di sejumlah kategori produk termasuk elektronik, makanan, barang perawatan pribadi, dan obat-obatan. Batra, Ahuvia, dan Bagozzi (2012) juga menunjukkan hubungan yang kuat antara cinta merek dan loyalitas merek dalam serangkaian tiga studi. Penelitian tentang pengaruh brand love terhadap loyalitas pernah dilakukan oleh Huang (2017). Penelitian tersebut meneliti merek telepon mobile di Taiwan. Hasilnya menunjukkan bahwa brand love berpengaruh pada loyalitas. Temuan ini 
sejalan dengan temua Drennan et al., (2015), Bicakglio et al., (2016) dan Khan et al., (2020)., Mody dan Hanks., (2020) yang juga menyampaikan bahwa terdapat pengaruh brand love terhadap loyalitas.

H2: Brand Love berpengaruh positif pada loyalitas

\section{Pengaruh satisfaction terhadap WOM}

Khan et al., (2020) melakukan penelitian tentang merek halal di Malaysia. Dalam penelitian tersebut ditemukan bahwa komponen kepuasan merupakan komponen yang berpengaruh secara positif dan signifikan terhadap word of mouth, Menurut penelitian tersebut. Santini et al., (2018) menemukan hasil yang serupa yakni kepuasan konsumen memiliki pengaruh terhadap word of mouth. Wang et al., (2017) melakukan penelitian tentang pariwisata. Hasil penelitian tersebut menunjukkan bahwa kepuasan konsumen memiliki pengaruh terhadap word of mouth. Selain itu, Tripathy (2017), Pop dan Woratschek (2017).dalam penelitiannya menemukan bahwa kepuasan berpengaruh pada word of mouth.

\section{H3: Kepuasan berpengaruh positif pada WOM}

\section{Pengaruh brand love terhadap WOM}

Penelitian tentang pengaruh brand love terhadap word of mouth sebelumnya pernah dilakukan oleh Karjaluoto et al., (2016). Penelitian tersebut meneliti tentang produk hedonic dan hasilnya menunjukkan bahwa variabel brand love bisa mempengaruhi WOM. Penelitian bicakglio et al., (2016) juga menemukan hasil yang sama dengan hasil penelitian di atas.

Penelitian yang dilakukan Anggraeni dan Rachmanita (2015) dan Ismail dan Melewar (2015) dalam konteks Merek Fashion sama-sama menemukan bahwa kecintaan konsumen terhadap merek dapat mempengaruhi konsumen dalam melakukan word of mouth. Dalam konteks yang berbeda Louriero et al., (2017) juga menemukan bahwa brand love menjadi factor yang dapat mempengaruhi word of mouth.

H4: Brand Love berpengaruh positif pada WOM

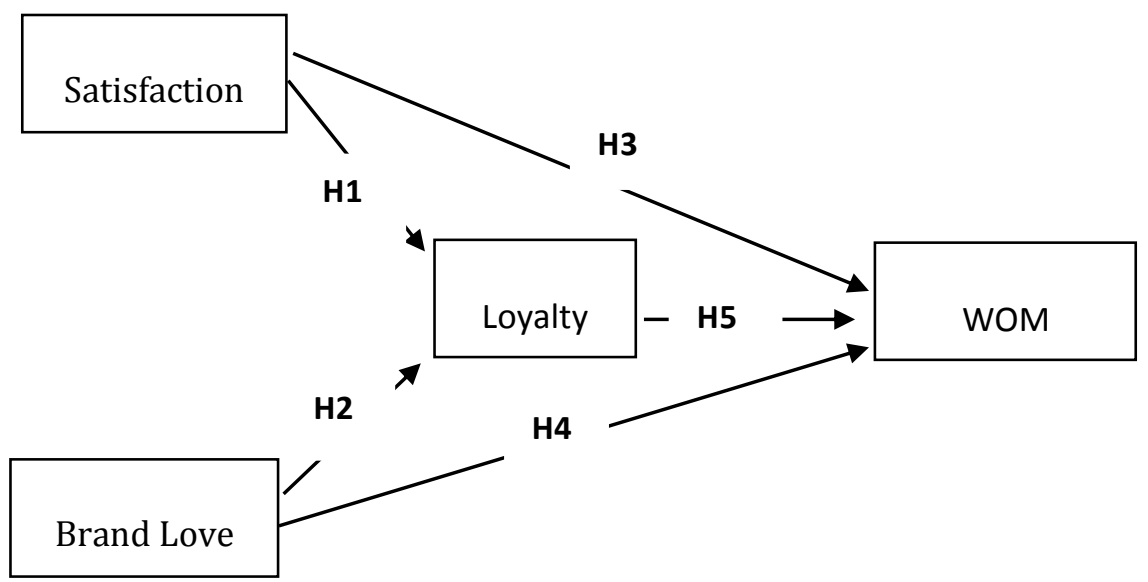

\section{Gambar 1}

Kerangka Model Penelitian

\section{Pengaruh loyalitas terhadap WOM}

Khan et al., (2020) melakukan sebuah penelitian tentang pengaruh loyalitas konsumen makanan cepat saja yang halal terhadap word of mouth dengan menggunakan objek merek-merek halal di 
Negara Malaysia. Temuan ini menunukkan bahwa variabel loyalitas memiliki dampak positif dan juga signifikan terhadap variable WOM. Temuan ini sesuai dengan temuan Bicakglio et al., (2016), yang menemukan bahwa loyalitas berdampak pada WOM.

Sejalan dengan penelitian di atas, Rialti et al., (2017) melakukan sebuah penelitian yang kaitannya dengan komunitas merek berbasis sosial media. Hasil penelitian tersebut menunjukkan bahwa loyalitas merupakan factor yang sangat berpengaruh pada $\mathrm{w}$

\section{H5: Loyalitas berpengaruh positif pada WOM}

\section{METODE}

\section{Teknik Sampling}

Teknik penentuan sampel yang digunakan dalam penelitian ini menggunakan teknik purposive sampling dimana responden yang terpilih menjadi sampel adalah konsumen yang pernah melakukan pembelian dan menggunakan Batik. Teknik pengambilan data melalui penyebaran kuisionerTarget responden dalam penelitian ini adalah konsumen batik Sumenep. Penelitian ini menggunakan sampel 200 responden. Jumlah ini sudah lebih banyak dari asumsi yang disampaikan oleh Hair et al., (2018) bahwa penentuan jumlah sampel yaitu jumlah sampel semestinya 5 sampai 10 kali jumlah indikator. Kemudian, 200 responden dianggap sudah cukup untuk melakukan pengujian menggunakan SEM.

\section{Variabel dan Indikator}

Variabel Kepuasan diukur menggunakan 4-item indikator yang diadaptasi dari Hussein (2018). Pertanyaannya misalkan, saya merasa puas terhadap merek batik ini dan Saya senang terhadap merek batik ini. Variabel brand love diukur menggunakan 5 -item pertanyaan yang diadaptasi dari Huang, (2017). Adapun contoh pertanyaan yaitu Merek batik ini adalah merek yang baik. Untuk variable Brand Loyalty diukur menggunakan 5 -item pertanyaan yang diadaptasi dari Kataria dan Saini (2019). Salah contoh pertanyaan adalah saya akan membeli merek batik ini di masa yang akan datang, saya berencana untuk terus membeli merek batik ini. Kemudian, untuk variabel word of mouth diukur menggunakan 3-item pertanyaan yang diadaptasi dari Bıçakcığlu et al., (2016). Adapun pertanyaannya seperti Saya akan mengatakan hal yang positif tentang merek batik ini dan lain sebagainya. Semua indicator yang digunakan untuk mengukur variabel menggunakan skala likert.

\section{Teknik Analisis}

Pemodelan persamaan menggunakan structural equation modeling (SEM) digunakan dalam penelitian ini. Pengolahan data dengan bantuan AMOS 21. Dalam penelitian ini, prosedur analisis data dibagi menjadi dua tahap:

\section{Model Pengukuran}

Validitas muka dan isi digunakan untuk menilai indikator yang digunakan untuk mengukur konstruk di awal. Validitas konvergen dan validitas diskriminan juga akan digunakan untuk mengevaluasi uji validitas konsep. Menggunakan nilai factor loading 0.50, menilai tingkat validitas masing-masing instrumen. Nilai akar kuadrat dari AVE dibandingkan dengan nilai korelasi antar 
Edy Purwanto \& M. Munir Syam AR

Satisfaction, Brand Love, Loyalty, WOM, Batik

konstruk untuk menentukan validitas diskriminan. Selanjutnya, aturan praktis untuk pengujian reliabilitas adalah 0,70. (Hair et al., 2014).

\section{Model Struktural}

Penelitian yang menggunakan model struktural perlu dilakukan analisis yang meliputi tahapan untuk menguji hubungan antara satu variabel laten dengan variabel laten lainnya. CFA digunakan dalam model pengukuran variabel penelitian. Pengaruh variabel independen terhadap variabel dependen kemudian dinilai dengan menggunakan analisis jalur.

\section{HASIL DAN PEMBAHASAN}

\section{Analisa Deskriptif}

Karakteristik responden dalam penelitian ini dapat dilihat dalam tabel di bawah ini:

Tabel 1.

Karakteristik Responden

\begin{tabular}{|c|c|c|c|c|}
\hline Kategori & Karakteristik & responden & $\begin{array}{c}\text { Percent } \\
\text { (\%) }\end{array}$ & Total \\
\hline \multirow[t]{2}{*}{ Jenis Kelamin } & Laki-laki & 95 & 47,5 & \multirow{16}{*}{$\begin{array}{c}200 \\
\text { resp. } \\
(100 \%)\end{array}$} \\
\hline & Perempuan & 105 & 52,5 & \\
\hline \multirow[t]{2}{*}{ Usia } & $\leqslant 20$ tahun & 73 & 36,5 & \\
\hline & $21-30$ tahun & 127 & 63,5 & \\
\hline \multirow[t]{4}{*}{ Pendidikan } & SMA & 188 & 94,0 & \\
\hline & Diploma & 8 & 4,0 & \\
\hline & Sarjana & 3 & 1,5 & \\
\hline & Master & 1 & 0,5 & \\
\hline \multirow[t]{4}{*}{ Pekerjaan } & ASN & 2 & 1,0 & \\
\hline & Mahasiswa/Pelajar & 171 & 85,5 & \\
\hline & Wiraswasta & 4 & 2,0 & \\
\hline & lainnya & 23 & 11,5 & \\
\hline \multirow[t]{4}{*}{ Pendapatan } & $\leqslant \mathrm{Rp} 1.000 .000$ & 181 & 90,5 & \\
\hline & Rp $1.000 .001-2.500 .000$ & 9 & 4,5 & \\
\hline & Rp 2.500.001 - 5.000.000 & 4 & 2,0 & \\
\hline & $\geqslant \operatorname{Rp} 5.000 .001$ & 6 & 3,0 & \\
\hline
\end{tabular}

Sumber: data primer diolah (2021)

Berdasarkan tabel 1 di atas diperoleh informasi mengenai profil responden yang digunakan dalam penelitian ini. Misalnya, untuk kategori jenis kelamin, laki-laki sebesar 95 responden $(47,5 \%)$ dan perempuan 105 responden (52,5\%). Dalam tabel tersebut juga dijelaskan mengenai karakteristik usia responden, pendidikan, pekerjaan, dan juga pendapatan responden.

\section{Model Pengukuran}

Uji validitas dalam penelitian dilakukan menggunakan confirmatory-factor-analysis (CFA). Dalam pengujian ditemukan bahwa semua item memiliki faktor loading di atas 0,5. Nilai Average variance extract dari variabel satisfaction $(0,678)$, Brand Love $(0,668)$, brand loyalty $(0,597)$, dan WOM $(0,667)$. Dengan demikian, semua konstruk laten yang digunakan dalam penelitian ini 
memenuhi kriteria AVE $>0,50$ sehingga data yang ada layak untuk digunakan (valid). Hasil pengujian validitas dijelaskan dalam tabel berikut:

Tabel 2.

Hasil Uji Validitas

\begin{tabular}{ccccc}
\hline Konstruk dan & \multicolumn{4}{c}{ Uji Validitas } \\
\cline { 2 - 5 } Item Pertanyaan & Factor Loading & AVE & $\sqrt{ } \boldsymbol{A V} \boldsymbol{E}$ & Keterangan \\
\hline Satisfaction & & 0,678 & 0,823 & \\
SAT1 &, 815 & & & Valid \\
SAT2 &, 849 & & & Valid \\
SAT3 &, 835 & & & Valid \\
SAT4 &, 794 & & & Valid \\
Brand Love & & 0,668 & 0,817 & \\
BL1 &, 841 & & & Valid \\
BL2 &, 818 & & & Valid \\
BL3 &, 848 & & & Valid \\
BL4 &, 771 & & & Valid \\
BL5 &, 806 & & Valid \\
Brand Loyalty & & 0,772 & \\
LOY1 &, 797 & & & Valid \\
LOY2 &, 747 & & Valid \\
LOY3 &, 799 & & Valid \\
LOY4 &, 747 & & & \\
LOY5 &, 770 & & & Valid \\
WOM & & & \\
AT2 &, 809 & 0,667 & 0,817 & Valid \\
AT3 &, 840 & & & Valid \\
AT4 &, 801 & & & \\
\hline
\end{tabular}

Sumber: data primer diolah (2021)

Hasil uji validitas diskriminan dapat diketahui dengan membandingkan value dari akar kuadrat dari AVE dengan nilai korelasi antar konstruk. Apabila hasil dari akar kuadrat dari AVE lebih besar dari hasil hubungan antar construct maka dinyatakan valid secara diskriminan. Hasil akar kuadrat dari AVE untuk variabel satisfaction $(0,823)$, brand love $(0,817)$, brand loyalty $(0,772)$, dan WOM $(0,817)$. Nilai akar kuadrat dari masing-masing variabel lebih besar daripada nilai hasil hubungan antar konstruk.

Hasil uji reliabilitas dalam penelitian ini dijelaskan dalam tabel di bawan ini: 
Tabel 3. Hasil Uji Reliabilitas

\begin{tabular}{lc}
\hline \multicolumn{1}{c}{ Variabel } & Construct Reliability \\
\hline Satisfaction & $\mathbf{0 , 8 9 4}$ \\
Brand Love & $\mathbf{0 , 9 0 9}$ \\
Brand Loyalty & $\mathbf{0 , 8 8 1}$ \\
WOM & $\mathbf{0 , 8 5 7}$ \\
\hline
\end{tabular}

Sumber: data primer diolah (2021)

Hair et al. (2014) menyampaikan bahwa apabila nilai reliabilitas lebih besar dari 0,70 dianggap memiliki reliabilitas yang baik. Adapun nilai realiabilitas dari variabel satisfaction $(0,894)$, brand love $(0,909)$, brand loyalty $(0,881)$, WOM $(0,857)$. Oleh karena itu, variabel yang digunakan dalam penelitian ini dinyatakan reliabel.

\section{Uji Model Struktural}

Sebelum menguji hipotesis, uji kesesuaian model harus ditentukan terlebih dahulu. Tabel berikut merangkum temuan-temuan goodness of fit dari model struktural:

Tabel 4.

Indeks Kesesuaian Model Struktural

\begin{tabular}{clccc}
\hline Tipe & \multicolumn{1}{c}{ Indeks } & Nilai Cut off & Hasil & Evaluasi \\
\hline Absolute fit & Chi-square & Diharapkan kecil & 222,509 & Baik \\
& p-value & $\geq 0,05$ & 0,000 & Marginal \\
& CMIN/DF & $2-5$ & 1,969 & Marginal \\
& GFI & $\geq 0,90$ & 0,883 & Marginal \\
& RMSEA & $\leq 0,80$ & 0,070 & Baik \\
Incremental fit & TLI & $\geq 0,90$ & 0,945 & Baik \\
& CFI & $\geq 0,90$ & 0,955 & Baik \\
Parsimony fit & AGFI & $\geq 0,90$ & 0,842 & Marginal \\
\hline
\end{tabular}

Sumber : data primer diolah 2021

Berdasarkan tabel di atas diketahui bahwa GOF untuk absolute fit dengan indeks Chi-square sebesar $(222,509)$, p-value $(0,000)$, CMIN/DF $(1,969)$, GFI $(0,883)$, RMSEA $(0,070)$. GOF untuk Incremental fit dengan indeks TLI $(0,945)$ dan CFI $(0,955)$. Kemudian, GOF untuk parsimony fit dengan indeks AGFI sebesar $(0,842)$. Dari kesemua indek GOF di atas terdapat 4 yang memenuhi kategori Baik yaitu Chi-square, RMSEA, TLI, DAN CFI. Menurut Hair et al. (2014), sebuah model dikatakan baik jika setidaknya tiga indeks memenuhi persyaratan kecocokan model. 


\section{Pembahasan Hasil Penelitian}

Berdasarkan temuan estimasi SEM dengan menggunakan pendekatan maximum likelihood, empat hipotesis berpengaruh positif dan signifikan, sedangkan satu hipotesis tidak berpengaruh. Lihat Tabel 5 untuk informasi lebih lanjut mengenai hasil pengujian hipotesis:

Tabel 5.

Hasil Uji Hipotesis

\begin{tabular}{cccccc}
\hline Hipotesis & $\begin{array}{c}\text { Standardized } \\
\text { Regression Weights }\end{array}$ & C.R. & $\mathbf{p}$ & Arah & Keterangan \\
\hline Hipotesis-1 & 0,257 & 2,410 &, 016 & + & Significan \\
Hipotesis-2 & 0,571 & 5,076 & $* * *$ & + & Significan \\
Hipotesis-3 & 0,392 & 4,050 & $* * *$ & + & Significan \\
Hipotesis-4 & 0,129 & 1,191 & 0,234 & + & Tidak \\
& & & & & Significan \\
Hipotesis-5 & 0,454 & 4,722 & $* * *$ & + & Significan \\
\hline
\end{tabular}

Sumber : data primer diolah 2021

Pengujian Hipotesis 1 menghasilkan nilai standardized regression weights diperoleh yaitu 0,257 dan signifika nsinya 0,016. Nilai ini menunjukkan bahwasanya kepuasan konsumen memiliki dampak yang positif dan signifikan pada loyalitas. Dengan nilai probabilitas lebih kecil dari 0,05 maka critical ratio (CR) sebesar 2,410 menunjukkan bahwa nilai CR di atas $\pm 1,96$. Akibatnya, dapat dinyatakan bahwa hipotesis 1 didukung dalam penelitian ini. Temuan ini mendukung pernyataan Ilias dan Shamsudin (2020) bahwa apabila konsumen merasa puas terhadap sebuah produk atau merek maka konsumen akan memberikan kesan yang baik di mata konsumen. Penelitian ini membuktikan bahwa kepuasan konsumen terhadap merek-merek batik yang ada di Kabupaten Sumenep seperti batik melati, batik canteng koneng, dan batik lainnya dapat mempengaruhi konsumen untuk tetap loyal baik dalam membeli maupun menggunakan merek tersebut. Sebuah meta analysis terhadap 256 penelitian kuantitatif dilakukan oleh santini et al., (2018). Hasil penelitian tersebut juga menemukan bahwa kepuasan konsumen berpengaruh pada loyalitas pelanggan. Hasil ini penelitian ini didukung oleh Ferreira et al., (2020) yang juga menemukan bahwa kepuasan konsumen Batik di kabupaten Sumenep bisa berdampak pada loyalitas. Demikian halnya dengan penelitian yang dilakulan oleh Huang et al., (2017), Pop dan Woratschek (2017), Giovanis dan athan (2018), Basser (2015), Hussein, (2018) yang juga menemukan bahwa kepuasan berpengaruh positif dan signifikan terhadap loyalitas konsumen.

Hasil pengujian hipotesis 2 dapat ditemukan bahwa nilai standardized regression weights yaitu 0,571 dan tingkat signifikansi 0,000. Nilai ini menunjukkan bahwa brand love berpengaruh secara positif signifikan pada loyalitas. Adapun hasil critical ratio (CR) yaitu 5,076 yang menunjukkan bahwasanya CR yang dihasilkan lebih besar dari $\pm 1,96$ dengan nilai probability lebih kecil dari 0,05. Mengacu pada nilai tersebut dapat diambil kesimpulan bahwasanya hipotesis 2 didukung. Hasil ini membuktikan bahwa kecintaan konsumen terhadap batik mendorong 
konsumen untuk loyal terhadap merek batik itu sendiri. Hal ini selaras dengan pernyataan Caroll dan Ahuvia (2006) yang menyampaikan bahwa keterikatan emosional yang dimiliki pelanggan yang senang terhadap suatu produk disebut sebagai cinta merek. Hasil penelitian ini didukung oleh penelitian Huang (2017) yang juga menemukan bahwa brand love berpengaruh terhadap loyalitas konsumen pada merek-merek telepon mobile. Demikian halnya dengan Penelitian yang dilakukan oleh Ferreira et al. (2020) tentang merek fashion di toko retail yang ada di Portugal menemukan bahwa kecintaan terhadap merek mempengaruhi loyalitas terhadap merek. Penelitian lain yang serupa dilakukan oleh Bçakcolu et al., (2016), Mody dan Hanks., (2020) dan Khan (2020), yang menemukan bahwa brand love memiliki pengaruh terhadap loyalitas konsumen.

Hasil pengujian hipotesis 3 diperoleh nilai regresi standardized regression weights sebesar 0,392 dan taraf signifikansi 0,000. Angka ini menunjukkan bahwa kepuasan pelanggan memiliki dampak positif terhadap word of mouth. Nilai CR yang dihasilkan sebesar 4.050, lebih besar dari $\pm 1,96$ dengan tingkat probabilitas lebih kecil dari 0,05. Dengan dimikian, Hipotesis 3 didukung dalam penelitian ini. Konsumen yang merasa puas terhadap sebuah produk akan menyampaikan sesuatu yang positif mengenai produk atau merek tersebut (Ilias dan Shamsudin, 2020). Dengan demikian kepuasan konsumen terhadap batik menjadi salah satu faktor yang sangat penting dalam memasarkan batik di Kabupaten Sumenep. Penelitian Khan et al., (2020), menghasilkan hasil yang selaras dengan temuin ini bahwa kepuasan konsumen memiliki pengaruh terhadap word of mouth. Penelitian tersebut meneliti makanan cepat saja yang halal di negara Malaysia. Selain itu, hasil penelitian Santini et al., (2018), Tripathy, (2017), Pop dan Woratschek (2017), Wang et al., (2017) di sektor pariwisata juga menemukan hasil yang sama dengan temuan dalam penelitian ini.

Berdasarkan pengujian hipotesis 4 ditemukan nilai standardized regression weights sebesar 0,129. Dengan tingkat signifikansi 0,234. Hasil ini menunjukkan bahwa brand love memiliki pengaruh yang positif tetapi tidak signifikan pada variable word of mouth. Dengan nilai probabilitas lebih besar dari 0,05, CR 1,191 menjelaskan bahwa CR yang dihasilkan lebih dari kecil dari 1,96. Atas dasar temuan ini, hipotesis 4 tidak didukung dalam penyelidikan ini. Temuan penelitian ini berbeda dengan hasil penelitian Karjuluto et al., (2016) dan Bicakglio et al., (2016). Perbedaan ini bisa terjadi perbedaan objek yang diteliti dan perbedaan lokasi penelitian. Penelitian ini dilakukan di Indonesia tepatnya di Kabupaten Sumenep. Variabel brand love sebetulnya memiliki pengaruh yang positif terhadap WOM akan tetapi angkanya belum signifikan. Berdasarkan interview yang dilakukan kepada responden, ditemukan informasi bahwa di mata konsumen, Batik di Kabupaten Sumenep merupakan sesuatu yang lumrah. Informasi mengenai batik sangat mudah diperoleh sehingga kecintaan konsumen terhadap batik tidak terlalu mempengaruhi konsumen untuk bercerita mengenai batik yang mereka beli atau gunakan.

Pengujian hipotesis 5 menghasilkan nilai standardized regression weights yaitu 0,454 dan tingkat signifikansinya yaitu 0,000 . Hal ini menunjukkan bahwasanya brand loyalty berpengaruh secara positif signifikan pada word of mouth. Adapun nilai critical rasionya yaitu 4,722 menunjukkan bahwasanya nilai Critical Ration lebih besar dari $\pm 1,96$ dengan tingkat probability lebih kecil dari 0,05. Berdasarkan nilai tersebut sehingga hipotesis 5 didukung dalam penelitian ini. Kandampully et al., (2015) menyampaikan bahwa loyalitas merupakan salah satu konsep dalam pemasaran yang telah dibuktikan sebagai konsep penting bagi perusahaan. Dalam penelitian ini, konsumen batik yang memiliki loyalitas terhadap batik yang mereka gunakan akan menyampaikan informasi-informasi yang postif kepada orang lain. Konsumen batik di Sumenep seperti Batik canteng koneng, batik melati dan batik lainnya dapat membantu memperkenalkan batik-batik yang ada sehingga startegi dalam membuat konsumen menjadi loyal terhadap batik perlu difikirkan dengan baik. Bicakglio et al., (2016), Rialti et al., (2017) dan Khan et al., (2020) 
yang sudah terlebih dahulu melakukan penelitian tentang pengaruh loyalitas konsumen terhadap word of mouth juga menemukan hasil sama dengan temuan dalam penelitian ini.

\section{KESIMPULAN DAN IMPLIKASI}

Kesimpulan yang dapat diambil dari penelitian ini, yaitu: (1) kepuasan konsumen merupakan variabel yang memiliki dampak pada loyalitas konsumen dan juga dapat mempengaruhi konsumen dalam menyampaikan informasi yang postif kepada konsumen yang lain. (2). Brand love merupakan variabel yang perlu diperhatikan karena kecintaan konsumen terhadap batik dapat membuat konsumen tetap membeli batik tersebut dimasa yang akan datang, akan tetapi hasil dalam penelitian menemukan bahwa brand love tidak berpengaruh pada WOM. (3) Loyalitas merupakan sebuah variabel yang perlu diperhatikan karena loyalias dapat mendorong konsumen untuk menyampaikan informasi kepada konsumen lain.

Kontribusi praktis penelitian ini yaitu dapat memberikan informasi tentang strategi yang perlu dilakukan dalam memperkenalkan batik dan seharusnya pelaku usaha Batik seharusnya memperhatikan faktor kepuasan konsumen, kecintaan konsumen terhadap Batik agar tercipta loyalitas konsumen sehingga konsumen juga mau menyampaikan informasi kepada orang-orang di sekitarnya. Secara empiris, penelitian ini diharapkan dapat menambah literatur tentang kepuasan, brand love, loyalitas dan WOM. Penelitian ini juga memperkaya kajian mengenai perilaku konsumen Batik yang ada di Kabupaten Sumenep.

\section{Keterbatasan dan Saran}

Keterbatasan dalam penelitian ini diantaranya, pertama, penelitian ini hanya dilakukan di satu wilayah yaitu Kabupaten Sumenep. Disarankan agar lebih banyak penelitian dilakukan di berbagai lokasi di Indonesia. Kedua, penelitian ini hanya menggunakan empat variabel yaitu kepuasan, brand love, loyalitas dan WOM sebagai variabel penelitian. Selanjutnya perlu dilakukan penelitian menggunakan variabel yang berbeda untuk memperkaya kajian. Ketiga, Penelitian ini fokus meneliti mengenai perilaku konsumen Batik, kedepannya perlu penelitian yang mengkaji mengenai bagaimana strategi industri Batik di Indonesia dalam bersaing di era saat ini. Keempat, penelitian ini mengambil data cross section sehingga penelitian selanjutnya perlu melakukan penelitian dengan pengambilan data bertahap dan di waktu yang berbeda.

\section{REFERENSI}

Anggraeni, A. (2015). Effects of brand love, personality and image on word of mouth; the case of local fashion brands among young consumers. Procedia-Social and Behavioral Sciences, 211, 442-447.

Bagozzi, R. P., Batra, R., \& Ahuvia, A. (2017). Brand love: development and validation of a practical scale. Marketing Letters, 28(1), 1-14.

Bairrada, C. M., Coelho, A., and Lizanets, V. (2019). The impact of brand personality on consumer behavior: the role of brand love. Journal of Fashion Marketing and Management: An International Journal.

Başer, İ. U., Cintamür, İ. G., and Arslan, F. M. (2015). Examining the Effect of Brand Experience on Consumer Satisfaction, Brand Trust and Brand Loyalty. Marmara University Journal of Economic \& Administrative Sciences, 37(2). 
Batra, Rajeev, Aaron Ahuvia, and Richard P. Bagozzi. 2012. "Brand Love." Journal of Marketing 76 (2): 1-16.

Bergkvist, Lars, and Tino Bech-Larsen. 2010. "Two Studies of Consequences and Actionable Antecedents of Brand Love." Journal of Brand Management 17 (7): 504-18.

Berger, J. (2014). Word of Mouth and Interpersonal Communication: A Review and Direction for Future Research Journal of Consumer Psychology, 24(4), 586-607.

Bıçakcıŏlu, N., İpek, İ., and Bayraktaroğlu, G. (2016). Antecedents and outcomes of brand love: the mediating role of brand loyalty. Journal of Marketing Communications, 24(8), 863-877.

Carroll, B. A., dan Ahuvia, A. C. (2006). Some antecedents and outcomes of brand love. Marketing letters, 17(2), 79-89.

Coelho, P.S., Rita, P. and Santos, Z.R. (2018), "On the relationship between consumer brand identification, brand community and brand loyalty", Journal of Retailing and Consumer Services, 43(3), 101-11.

Drennan, J., Bianchi, C., Cacho-Elizondo, S., Louriero, S., Guibert, N., \& Proud, W. (2015). Examining the role of wine brand love on brand loyalty: A multi-country comparison. International Journal of Hospitality Management, 49, 47-55.

Ferreira, P., Rodrigues, P., dan Rodrigues, P. (2019). Brand love as mediator of the brand experience-satisfaction-loyalty relationship in a retail fashion brand. Management \& Marketing. Challenges for the Knowledge Society, 14(3), 278-291.

Flint, D.J., Blocker, C.P. and Boutin, P.J. (2011), "Customer value anticipation, customer satisfaction and loyalty: An empirical examination", Industrial Marketing Management, 40(2) 219-230.

Giovanis, A.N. and Athanasopoulou, P. (2018), "Consumer-brand relationships and brand loyalty in technology-mediated services", Journal of Retailing and Consumer Services, 40(1), 287294.

Hair J. F., Black, W. C., Babin, B. J., and Anderson, R. E. (2014), Multivariate data Analysis (7th ed.). Pearson Education Limited.

Hair, J. F., Black, W. C., Babin, B. J., and Anderson, R. E. (2018). Multivariate Data Analysis. Cengage.

Huang, C. C. (2017). The impacts of brand experiences on brand loyalty: mediators of brand love and trust. Management Decision. 55(5), 915-934

Hussein, A. S. (2018). Effects of brand experience on brand loyalty in Indonesian casual dining restaurant: Roles of customer satisfaction and brand of origin. Tourism and hospitality management, 24(1), 119-132.

Ismail, A. R., \& Melewar, T. C. (2015). Binational study of the impact of brand image, brand personality and brand love on word of mouth: The case of fashion brands in UK and Switzerland. In Marketing Dynamism \& Sustainability: Things Change, Things Stay the Same (pp. 462-471). Springer, Cham.

Ilias, S., \& Shamsudin, M. F. (2020). Customer Satisfaction and Business. Journal of Undergraduate Social Science and Technology, 2(2).

Kandampully, J., Zhang, T. C., and Bilgihan, A. (2015). Customer loyalty: a review and future directions with a special focus on the hospitality industry. International Journal of Contemporary Hospitality Management. 27(3), 379-414

Karjaluoto, H., Munnukka, J., and Kiuru, K. (2016). Brand love and positive word of mouth: the moderating effects of experience and price. Journal of Product \& Brand Management. 
Kataria, S., and Saini, V. (2019). The mediating impact of customer satisfaction in relation of brand equity and brand loyalty: An empirical synthesis and re-examination. South Asian Journal of Business Studies. 9(1), 62-87

Khan, A., Mohammad, A. S., and Muhammad, S. (2020). An integrated model of brand experience and brand love for halal brands: survey of halal fast food consumers in Malaysia. Journal of Islamic Marketing.

Khan, M. T. (2013). Customer loyalty: Concept \& definition (a review). International Journal of Information, Business and Management, 5(3), 168-191.

Kimmel, A. J. (2010). Connecting with Consumer. United Kingdom: Oxford University Press.

Loureiro, S. M. C., Gorgus, T., \& Kaufmann, H. R. (2017). Antecedents and outcomes of online brand engagement: The role of brand love on enhancing electronic-word-of-mouth. Online Information Review. 4 (7), 985-1005

Mody, M., \& Hanks, L. (2020). Consumption authenticity in the accommodations industry: the keys to brand love and brand loyalty for hotels and Airbnb. Journal of Travel Research, 59(1), 173-189.

Niyomsart, S., dan Khamwon, A.(2015). Brand Love, Brand Loyalty, and Word of Mouth: A Case of AirAsia. Paper presented at the International Journal of Arts \& Sciences' (IJAS) International Conference for Business and Economics, Rome, Italy.

Pappu, R. and Quester, P.G. (2016), "How does brand innovativeness affect brand loyalty?", European czxbmJournal of Marketing, 50 )1-2), pp. 2-28.

Popp, B., \& Woratschek, H. (2017). Consumer-brand identification revisited: An integrative framework of brand identification, customer satisfaction, and price image and their role for brand loyalty and word of mouth. Journal of Brand Management, 24(3), 250-270.

Prayitno, T. (2020). Mengenal Produk Nasional Batik dan Tenun. Alprin.

Razak, A. A., \& Shamsudin, M. F. (2019). The influence of atmospheric experience on Theme Park Tourist's satisfaction and loyalty in Malaysia. International Journal of Innovation, Creativity and Change, 6(9), 10-20.

Rialti, R., Zollo, L., Pellegrini, M. M., \& Ciappei, C. (2017). Exploring the antecedents of brand loyalty and electronic word of mouth in social-media-based brand communities: do gender differences matter? Journal of Global Marketing, 30(3), 147-160.

Roy, S. K., Eshghi, A., and Sarkar, A. (2013). Antecedents and consequences of brand love. Journal of Brand Management, 20(4), 325-332.

Rubio, N., Villase nor, N. and Yague, M.J. (2017), "Creation of consumer loyalty and trust in the retailer through store brands: the moderating effect of choice of store brand name", Journal of Retailing and Consumer Services, 34 (1), 358-368.

Santini, D, O, F., Ladeira, W. J., Sampaio, C. H., \& Pinto, D. C. (2018). The brand experience extended model: A meta-analysis. Journal of Brand Management, 25(6), 519-535.

Sari, A., Ambarwati, D. A. S., and Ramelan, M. R. (2020). The mediation relationship of customer satisfaction between service quality and repurchase intention on $\mathrm{e}$ commerce in Indonesia. Jurnal Manajemen dan Pemasaran Jasa, 13(1), 137-150.

Tabaku, E., and Zerellari, M. (2015). Brand loyalty and loyalty programs: A literature review. Romanian Economic and Business Review, 10(2), 71-86 
Tripathi, G. (2017). Customer satisfaction and word of mouth intentions: testing the mediating effect of customer loyalty. Journal of Services Research, 17(2), 1-16.

Wang, T. L., Tran, P. T. K., \& Tran, V. T. (2017). Destination perceived quality, tourist satisfaction and word-of-mouth. Tourism Review. 


\section{Competing interests}

The authors declare that they have no competing interests

\section{Funding.}

The authors received no financial support for the research and publication of this article

\section{About the Authors}

Edy Purwanto merupakan dosen Fakultas Ekonomi dan Bisnis Universitas Wiraraja di Sumenep. Pada tahun 2017, Penulis lulus dari Universitas Gadjah Mada dengan gelar magister sains manajemen (M.Sc) di bidang pemasaran. Minat penelitian: strategi pemasaran, Merek, dan perilaku konsumen. Alamat email penulis yaitu edypurwanto@wiraraja.ac.id 